\title{
The Ecosystem Service Controversy: Is There Sufficient Evidence for a "Pollination Paradox"?
}

\author{
Reaction to J. Ghazoul. 2007. Recognising the complexities of ecosystem \\ management and the ecosystem service concept. GAIA 16/3: 215-221
}

Alexandra-Maria Klein, Roland Olschewski, Claire Kremen

\author{
The Ecosystem Service Controversy: Is There Sufficient Evidence for a \\ “Pollination Paradox"? | GAIA 17/1 (2008): 12-16 \\ Keywords: almond, biodiversity, coffee, crop pollination, ecosystem services, sustainability
}

\section{The Ecosystem Service Controversy}

Ecosystem services have gained increasing recognition as important components of land management strategies (e.g. Kremen 2005, Díaz et al. 2006). As a prerequisite for adopting sustainable management practices, ecological and economic research is needed to assess the contribution of ecosystem services to both conservation and development. In his recent GAIA article, Jaboury Ghazoul argues that ecosystem service approaches are often "motivated by scientists' desire to protect and conserve wild species and semi-natural habitats" (Ghazoul 2007). According to him, the ecosystem service concept is promoted by scientists who link ecosystem functions to human well-being, but has not found wide-spread acceptance among local actors. Furthermore, Ghazoul argues convincingly that economic evaluations of single services should not be used as the main argument for nature conservation because only a good balance of many ecosystem services leads to economic benefits for humans.

His article chiefly refers to a single ecosystem service - crop pollination - to highlight that evaluation of single ecosystem services is not appropriate without taking other functions and services into account. Ghazoul presents a "paradox", as he describes it, meaning crops depend on pollinators but crop yield does not necessarily depend on pollinators as other factors are likely to limit crop production. Although this is fairly argued, we will show

Contact: Dr. Alexandra-Maria Klein | Department of Crop Science | Agroecology | University of Göttingen | Waldweg 26 | 37073 Göttingen | Germany | Tel.: +49 551392257 | E-Mail: aklein2@gwdg.de also: Environmental Sciences, Policy and Management | University of California | Berkeley, CA | USA

PD Dr. Roland Olschewski | Swiss Federal Research Institute WSL | Birmensdorf | Switzerland | E-Mail: roland.olschewski@wsl.ch

Prof. Dr. Claire Kremen | Environmental Sciences, Policy and Management | University of California | Berkeley, CA | USA |

E-Mail: ckremen@nature.berkeley.edu that given the data currently available, there is no evidence for a "pollination paradox". We will also discuss the potential pitfalls inherent to the study of pollination services, highlighting the importance of existing studies and the need for future research projects to capture the multiple dimensionalities and to visualize trade-offs between ecological and economic aspects.

We generally agree that ecological and economic assessments and evaluations of ecosystem services for crop production have to include interactions of ecosystem services (Bos et al. 2007, Kremen et al. 2007). However, we are concerned that presenting hypothetical paradoxes that are only partially backed up by appropriate examples can be misleading for the scientific debate, and may hinder rather than promote a meaningful dialogue among the stakeholders involved.

\section{Potential Pitfalls in Assessing Pollination Services}

The importance of pollinators to fruit and seed quantity and quality has recently been reviewed for the first time at global scale (Klein et al. 2007). As cited by Ghazoul, most crops do not totally depend on pollinators, i.e., only 13 globally important crops would be entirely unable to set fruit if pollinators were absent (Klein et al. 2007). However, the majority of crops -75 percent - showed a reduction of fruit quality or quantity, or both, when pollinators were excluded experimentally (Klein et al. 2007). In various currently available valuation studies, crop pollination services have been determined based on data from experiments at plant scale or even at finer spatial scales such as subsets of flowers per plant (e.g. Ricketts et al. 2004, Morandin and Winston 2006, Losey and Vaughan 2006, Olschewski et al. 2006 and 2007). The pitfall Ghazoul mentions is that there exists practically no experimental evidence that pollinators increase fruit quantity at larger scales such as on whole farms. He argues that other factors like water, nutrients, and pest control are more likely to limit yield at the farm scale, and that therefore pollination, although a key ecosystem service, is usually not the limiting factor for crop 
yield (production per unit area). Although this may indeed be correct in some cases, evidence is lacking for a "pollination paradox", i.e., Ghazoul's general statement that crop yield in agricultural systems is usually not limited by pollinators. This is a young field of research; thus we still lack whole-farm assessment studies. We agree that research is urgently needed to determine how each single ecosystem service contributes to the eventual crop yield and to the farmer's profit (Bos et al. 2007, Zhang et al. 2007). However, such studies are considered difficult to conduct (Kremen et al. 2007). In fact, ongoing research projects that do such research on a landscape scale are encountering difficulties. Addressing these difficulties and developing an integrated approach are important tasks in order to determine the value of (wild) pollinators and/or to what extent habitat conservation may promote pollinator diversity and abundance.

\section{The "Pollination Paradox" for Coffee Production}

Natural habitats in the vicinity of coffee plantations, as well as extensive agroforestry management, can increase pollination services (normally measured as pollen deposition, pollen tube growth and fruit set ${ }^{1}$ ) for highland coffee. This has been shown on different continents and under different management conditions (Klein et al. forthcoming), even though highland coffee is self-compatible (Klein et al. 2003). Again, at the farm scale, experimental data relating crop yield and farmer's profit to the pollination service are still missing. Whilst searching for evidence for the "inconsistencies of the ecosystem service concept", Ghazoul cites Campanha et al. (2004) and argues that intensive coffee monocultures "remain far more productive" than less intensively managed coffee agroforests, although monocultures may have fewer pollinators (De Marco and Coelho 2004). Ghazoul's argument centers on a study that extrapolates plant growth and fruit number from within-plant and plant scales, respectively, to the farm scale (Campanha et al. 2004). Since Ghazoul has fairly recognized that extrapolating from plant (and especially from within-plant) scales to the farm scale is fraught with complexities, it is inconsistent then to utilize such extrapolations. Making the point that intensified systems are more productive than extensively managed ones (Ghazoul 2007), it should also

1 Fruit set: transition of the flower to the fruit.

FIGURE 1: An almond orchard in full bloom. If pollination rarely limits crop production - as Jaboury Ghazoul postulates in his recent GAIA article -, then why do so many farmers in the world, and especially Californian almond farmers, rely on managed honeybee colonies?

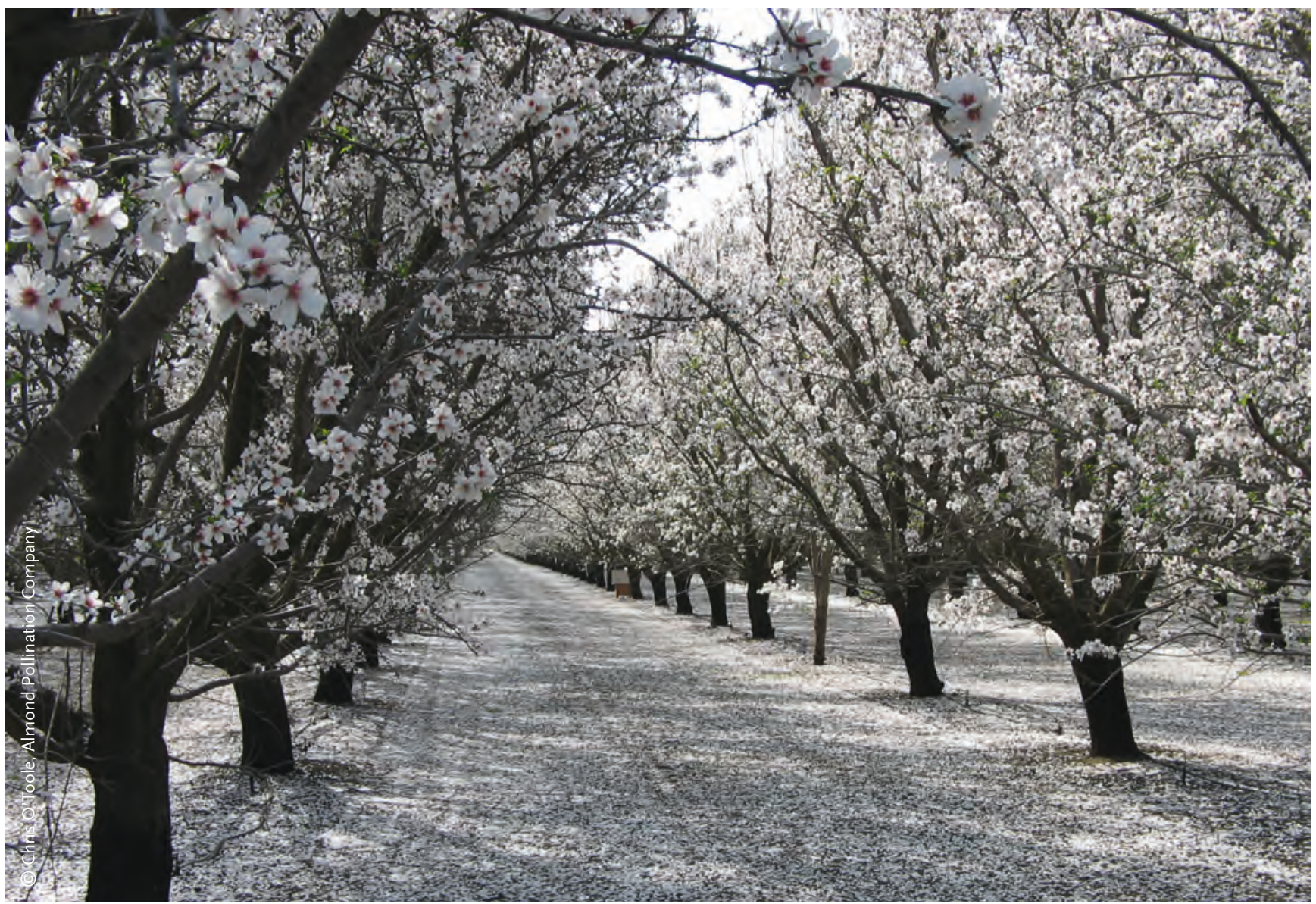


be considered that yield comparisons between shaded and nonshaded systems in coffee have produced different results in different studies. It has been shown that non-shaded, intensively managed systems are more productive, both as concerns plant growth and number of berries (Soto-Pinto et al. 2000, Campanha et al. 2004). However, moderately shaded systems can be even more productive than intensive, non-shaded systems (Amoah et al. 1997). ${ }^{2}$ We conclude that more research under standardized conditions is urgently needed to compare coffee yields between unshaded monocultures and shaded agroforests.

Finally, the results of the studies mentioned - that measure yield per farm - cannot be related to pollination unless the pollination fauna and the pollination processes occurring in the study sites are known. Some coffee-pollinating bees increase in abundance with land-use intensification (Klein et al. 2002). Moreover, coffee varieties vary in their demand for pollination services: On the one hand, there are varieties where fruit set increases by up to 25 percent due to pollination; on the other hand, some sungrown varieties do not profit at all from insect visitation. ${ }^{3}$ In sum, these studies on coffee yield provide no evidence either for or against the "pollination paradox".

\section{The "Sustainability Conflict" in Almond Pollination}

Almond pollination is the second example presented by Ghazoul to demonstrate the "pollination paradox". He states that although honeybee colonies in the United States have declined from 1989 to 2004, Californian almond yields per hectare have continued to rise during the period from 1996 to 2006. Does this really support the "pollination paradox"? For various reasons, this comparison is difficult to interpret. From 1989 to 1998, for instance, total honeybee colonies decreased in the United States, but the number of colonies rented for almond pollination increased (Morse and Calderone 2000). Thus, the pertinent question is whether farmers were able to stock their farms with sufficient honeybee colonies, i. e., two to four hives per hectare. ${ }^{4}$ If so, almond farmers must have been able to meet their demand for pollination services despite increasing almond acreage and despite the national decline in the number of honeybee colonies.

Almond cropping in California is heavily dependent on managed pollinators because almond trees bloom very early in the year - at the end of the winter season - when wild pollinators are still rare (figure 1). Hence, Californian almond farmers must rent honeybees to ensure pollination. Bee rental fees for almond pollination have more than doubled during the last several years from about 50 USD to about 120 USD per hive (Stokstad 2007). Beekeepers and almond farmers in California have trucked in honeybee hives from as far as Florida and have re-populated weak hives with air-freighted bees from Australia, indicating the extremes they take and already took to obtain the necessary input. Some farmers even buy expensive compatible pollen ${ }^{5}$ from private companies and put them into beehives to promote the transfer of compatible pollen to their most important almond varieties in order to enhance fruit set. Others buy brood pheromones to increase honeybee foraging activity. ${ }^{6}$ Farmers' increased expenditures to rent bees, transport bees or employ expensive technologies to increase pollination success all indicate a shortage in the supply of pollination services, and provide perfect evidence for the economic importance of pollination. However, the honeybee shortage might be caused by several factors such as increased pollinator demand due to the extension of almond acreage during the last years (Sumner and Boriss 2006) and reduced honeybee supply due to stress and diseases (Stokstad 2007). As a consequence, not only ecological but also economic complexity should be taken into account to avoid misinterpretations.

This leads us to the "sustainability conflict" between ecological sustainability and economic productivity postulated by Ghazoul, i. e., a decline in bee colonies does not seem to prevent almond farmers from increasing their profits. If managed bee colonies are a suitable substitute for natural habitats, why bear the opportunity costs of conserving or restoring land as habitat for bees? One argument in favor of land conservation is that it may minimize the risk of relying on an increasingly scarce and variable resource, the European honeybee (NRC 2006), which is vulnerable to an unexplained phenomenon called "Colony Collapse Disorder” (Stokstad 2007). Nevertheless, almond pollination in California seems to be a rather inadequate example to demonstrate a "sustainability conflict" in the management of pollination services: Non-managed bees alone are unlikely ever to provide adequate pollination services because of the high demand of pollinators and the early time of almond blooming.

Furthermore, we would like to emphasize that several studies have already conducted cost-benefit analyses and considered opportunity costs (e.g. Balmford et al. 2002, Naidoo and Ricketts 2006) regarding pollination services. Olschewski et al. (2006) showed that coffee farmers' profit would be much higher if pollinator habitats were replaced by land-use alternatives that do not depend on pollinators instead of conserving these habitats hoping for adequate pollination services. Morandin and Winston (2006), in contrast, developed a landscape model estimating the economic effect of leaving different proportions of land uncultivated as bee habitat.

Although it is difficult to demonstrate win-win scenarios combining economic and conservation advantages (Naidoo and Ricketts 2006, Chan et al. 2007), pollination services might be recognized and maintained without relying predominantly on

2 For a review, see Beer et al. (1998).

3 A.-M. Klein et al.: unpublished data.

4 The number of colonies needed depends on weather conditions.

5 Compatible pollen: pollen that can turn the female reproductive organ of the flower into a fruit. Commercial almond varieties in California are selfincompatible, i.e., the flower can only develop a nut when pollen of another variety is transferred to the female reproductive organ.

6 A.-M. Klein: personal communications with farmers and companies selling pollen and pheromones. 


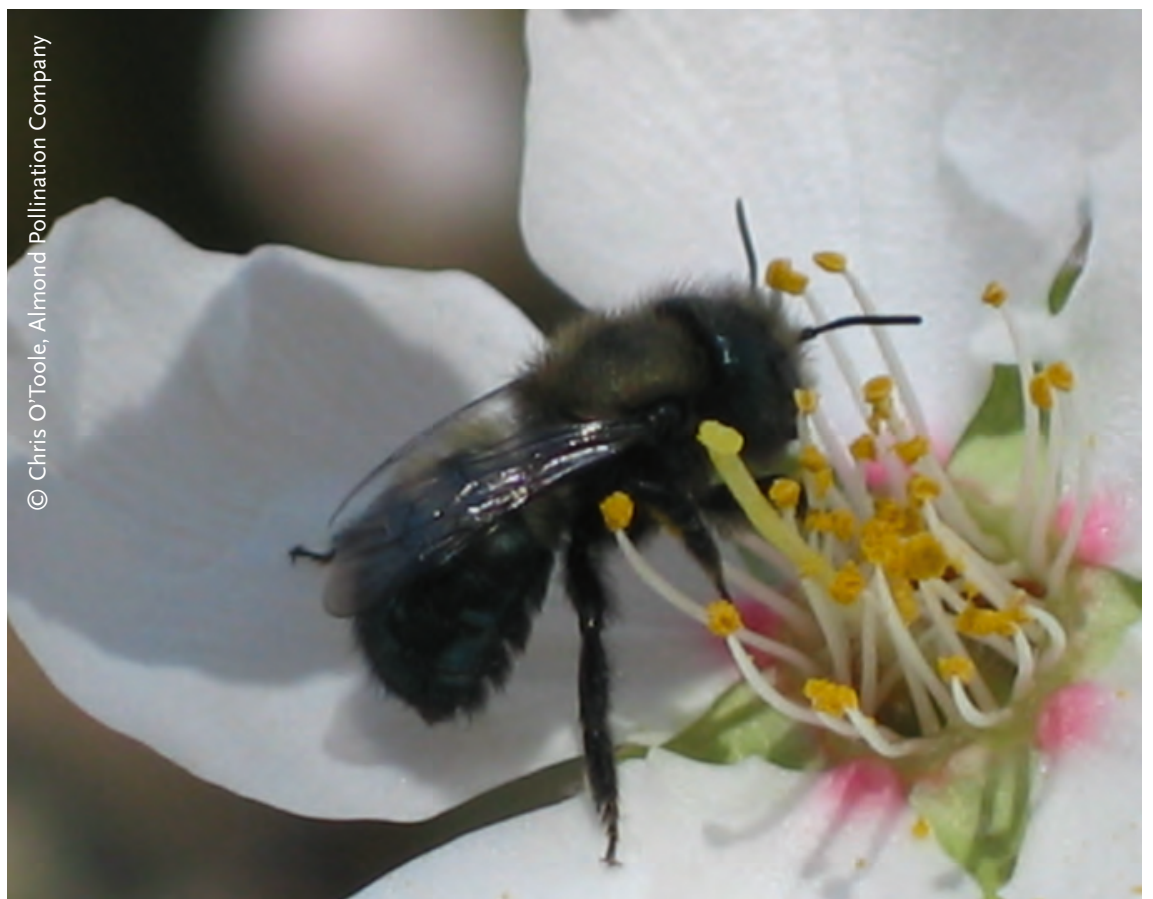

FIGURE 2: Female blue orchard bee, Osmia lignaria propinqua Cresson, a non-honeybee foraging on an almond flower in Southern California. Large, intensive almond monocultures provide few nesting resources for pollinators (e.g. bees) and scarce floral resources outside the short almond blooming period. Therefore, wild pollinators can never provide adequate pollination services in such orchards. Only when orchards border semi-natural habitats, wild pollinators forage in almond orchards (C. Kremen, unpublished data). Hence, we consider almond pollination in California rather inadequate to exemplify a "sustainability conflict" - i. e., a decline in bee colonies does not reduce farmers' profits - as Jaboury Chazoul argued in his recent GAIA article.

substitution. For example, some of California's almond farmers are interested in learning how to manage their habitats to increase non-managed pollinators (e.g. non-honeybees, see figure 2). Hence, the Xerces Society, an international non-profit organization in the United States, recently organized a meeting informing Californian almond farmers about ways to improve wild bee habitats on their land. Any of the actions proposed to promote wild bee pollinators would also promote feral and managed honeybees (NRC 2006) and might reduce the risk of insufficient pollination services in the future.

\section{Current Knowledge and Limitations}

If Ghazoul is right and pollination rarely limits crop production, then why do so many farmers in the world and especially in California rely on managed honeybee colonies? Why do they resort to non-honeybee pollination services or technical solutions to increase pollination success, even when growing crops or crop varieties that have a degree of autonomous self-pollination? Californian farmers are exceptionally well-informed about pollination and a suite of other management practices. Those growing highly pollinator-dependent crops care about pollination services, and some of them are interested in managing their orchards and fields to protect and promote wild pollinators. ${ }^{7}$ Recognizing the current limited state of knowledge, we aim at contributing to the scientific debate and to a meaningful stakeholder dialogue. We reply to Ghazoul's article to emphasize that in our eyes there is currently no evidence for a "pollination paradox".

On the other hand, we are also aware of possible overestimations of the value of pollination services, partly driven by media. Today, we still do not have basic information such as how important pollinators and their habitats are for human food production in terms of volume, economic value, and nutritional value beyond the simply caloric value (e. g. vitamins, proteins). The widely cited statement that one third of the caloric value of our food is derived from animal pollination is a rough estimate originally published by McGregor (1976). This figure is still not well supported, although Klein et al. (2007) found that up to 35 percent of crop production globally depends on pollinators to some degree. According to this latter study, we would lose six percent of the total global crop production when producing without pollinators. ${ }^{8}$ Possible consequences for our diet are yet unknown. Considering other nutritional values than only the caloric value, as well as indirect nutritional consequences of animal pollination (e.g. production of animal products, seed production for crop breeding, etc.) makes assessments even more complex than what has been attempted to date.

Finally, Ghazoul did not acknowledge possible indirect advantages wild pollinators may have for agriculture. Such positive effects include the conservation of genetic diversity in wild relatives of animal-pollinated crops as well as other ecosystem services like pest, water, and flood control provided by animal-pollinated wild plants in line with sustainable agriculture (Kremen et al. 2007). The importance of pollination services with regard to wild plant reproduction and nature conservation needs to be studied in respect of other factors limiting reproduction.

Determining the potential of managing agricultural landscapes for conserving pollinator habitats in a comprehensive sustainable way is one of the important challenges within the developing field of ecosystem services research. We agree with Ghazoul that fully recognizing ecological and economic complexities is a prerequisite for a successful adoption of appropriate management practices.

7 A.-M. Klein and C. Kremen: personal communications with almond farmers. 8 A.-M. Klein: unpublished data. 
A.-M. Klein is supported by the Alexander von Humboldt Foundation in the Feodor Lynen Program. Brian Gross and two anonymous reviewers provided valuable comments on this paper.

\section{References}

Amoah, F. M., K. Osei-Bonsu, F. K. Oppong. 1997. Response of improved robusta coffee to location and management practices in Ghana. Experimental Agriculture 33: 103-111.

Balmford, A. et al. 2002. Economic reasons for conserving wild nature. Science 297: 950-953.

Beer, J., R. Muschler, D. Kass, E. Somarriba. 1998. Shade management in coffee and cacao plantations. Agroforestry Systems 38: 139-164.

Bos, M. M. et al. 2007. Caveats to quantifying ecosystem services: Fruit abortion blurs benefits from crop pollination. Ecological Applications 17: 1841-1849.

Campanha, M. M. et al. 2004. Growth and yield of coffee plants in agroforestry and monoculture systems in Minas Gerais, Brazil. Agroforestry Systems 63: $75-82$.

Chan, K. M. A. et al. 2007. When agendas collide: Human welfare and biological conservation. Conservation Biology 21: 59-68.

De Marco, P., F. M. Coelho. 2004. Services performed by the ecosystem: Forest remnants influence agricultural cultures' pollination and production. Biodiversity and Conservation 13: 1245-1255.

Díaz, S., J. Fargione, F. S. Chapin, D. Tilman. 2006. Biodiversity loss threatens human well-being. Public Library of Science Biology 4/8 (online): e277 doi:10.1371/journal.pbio.0040277.

Ghazoul, J. 2007. Recognising the complexities of ecosystem management and the ecosystem service concept. GAIA 16/3: 215-221.

Klein, A.-M., S. Cunningham, M. M. Bos, I. Steffan-Dewenter. Forthcoming. Advances in pollination ecology from tropical plantation crops. In: Agroforestry systems as model systems for tropical ecology. Edited by R. Greenberg, S. Philpott, I. Perfecto. Ecology Special Issue.

Klein, A.-M., I. Steffan-Dewenter, D. Buchori, T. Tscharntke. 2002. Effects of land use intensity in tropical agroforestry systems on coffee flowervisiting and trap-nesting bees and wasps. Conservation Biology 16: $1003-1014$.

Klein, A.-M., I. Steffan-Dewenter, T. Tscharntke. 2003. Fruit set of highland coffee increases with the diversity of pollinating bees. Proceedings of the Royal Society of London B 270: 955-961.

Klein, A.-M. et al. 2007. Importance of pollinators in changing landscapes for world crops. Proceedings of the Royal Society of London B 274: 303-313.

Kremen, C. 2005. Managing ecosystem services: What do we need to know about ecology? Ecology Letters 8: 468-479.

Kremen, C. et al. 2007. Pollination and other ecosystem services produced by mobile organisms: A conceptual framework for the effects of land-use change. Ecology Letters 10: 299-314.

Losey, J. E., M. Vaughan. 2006. The economic value of ecological services provided by insects. BioScience 56: 311-323.

McGregor, S. E. 1976. Insect pollination of cultivated crop plants. Agriculture handbook 496. Washington, D. C.: Agricultural Research Service, US Department of Agriculture. http://gears.tucson.ars.ag.gov/book (accessed January 16, 2008).

Morandin, L. A., M. L. Winston. 2006. Pollinators provide economic incentive to preserve natural land in agroecosystems. Agriculture, Ecosystems and Environment 116: 289-292.

Morse, R., D.W. Calderone. 2000. The value of honey bees as pollinators of U.S. crops in 2000. Ithaca, NY: Cornell University. www.masterbeekeeper.org/ pdf/pollination.pdf (accessed January 16, 2008).

Naidoo, R., T. H. Ricketts. 2006. Mapping the economic costs and benefits of conservation. Public Library of Science Biology 4/11 (online): e360 doi:10.1371/journal.pbio.0040360.

NRC (National Research Council of the National Academies). 2006. Status of pollinators in North America. Washington, D. C.: National Academy Press.
Olschewski, R., T. Tscharntke, P. C. Benitez, S. Schwarze, A.-M. Klein. 2006. Economic valuation of pollination services comparing coffee landscapes in Ecuador and Indonesia. Ecology and Society 11/7 (online): www.ecologyandsociety.org/vol11/iss 1/art7.

Olschewski, R., T. Tscharntke, P. C. Benítez, S. Schwarze, A.-M. Klein. 2007. Economic evaluation of ecosystem services as a basis for stabilizing rainforest margins? In: The stability of tropical rainforest margins: Linking ecological, economic and social constraints of land use and conservation. Edited by T. Tscharntke et al. Environmental Science Series. Berlin: Springer. 265-278.

Ricketts, T., G. C. Daily, P. R. Ehrlich, C. D. Michener. 2004. Economic value of tropical forest to coffee production. Proceedings of the National Academy of Science 101/34: 12579-12582.

Soto-Pinto, L., I. Perfecto, J. Castillo-Hernandez, J. Caballero-Nieto. 2000. Shade effect on coffee production at the northern Tzeltal zone of the state of Chiapas, Mexico. Agriculture, Ecosystems and Environment 80/1: 61-69.

Stokstad, E. 2007. The case of the empty hives. Science 316: 970-972.

Sumner, D. A., H. Boriss. 2006. Bee-conomics and the leap in pollination fees. Giannini Foundation of Agricultural Economics. http://aic.ucdavis.edu/ research/bee-conomics-1.pdf (accessed January 16, 2008).

Zhang, W., T. H. Ricketts, C. Kremen, K. Carney, S. M. Swinton. 2007. Ecosystem services and dis-services to agriculture. Ecological Economics 64: $253-260$.

Submitted October 17, 2007; revised version accepted December 20, 2007

\section{Alexandra-Maria Klein}

Born 1972 in Göttingen, Germany. Studies in biology, $\mathrm{PhD}$ in agroecology and entomology (thesis on coffee pollination) in 2003, both at the University of Göttingen. Postdoc on the effects of land use changes for biodiversity in Ecuador. Since 2005 research fellow in the Department of Crop Science at the University of Göttingen. Currently, she is working on an almond pollination project financed by the Alexander von Humboldt Foundation at the University of California, Berkeley.

\section{Roland Olschewski}

Born 1963 in Salzderhelden, Germany. PhD in economics in 1997. From 1997 to 2007 lecturer in environmental, forest and development economics at the University of Göttingen, Germany, and head of several interdisciplinary research projects. Since 2007 head of the research group

"Environmental and Resource Economics" at the Swiss

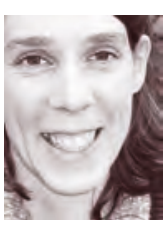

Federal Research Institute WSL in Birmensdorf, Switzerland. Main interests: forest economics, economic valuation of environmental services.

\section{Claire Kremen}

Born 1960 in Boston, USA. PhD in zoology in 1987. Collaboration with various conservation organizations in the United States and Madagascar. Assistant professor at Princeton University from 2001 to 2005 and since 2005 at the University of California, Berkeley. Main interest: developing conservation plans (based on biological,

social, and economic data) that benefit both the environment and humans, e.g., designing reserve networks in Madagascar and managing landscapes for ecosystem services in California. 